\title{
Comparative Assessment of Patient Care Expenses among Intensive Care Units of a Tertiary Care Teaching Hospital using Cost Block Method
}

\author{
Kanakavalli Kiranmai Kundury, H. K. Mamatha, Divya Rao \\ Department of Health System Management Studies, Jagadguru Sri Shivarathreeswara University, Mysuru, Karnataka, India
}

\section{Abstract}

Introduction: Intensive care services of a hospital are found to consume major chunk of hospital resources as well draining the savings of patients. Implementing proper control measures facilitates effective functioning of critical care services. Aim: Identify various costs involved in operating Surgical Intensive Care Unit (SICU) and Respiratory Intensive Care Unit (RICU); also find out the running cost of the same. Methodology: Retrospective data was collected for 12 months period and prospectively through informal interactions with staff. Results: Construction and estate costs of the respective ICU's were found to be high, followed by laboratory charges. Running cost of RICU was found to be more than SICU. Conclusion: Costing of intensive care service is essential for controlled operations and to provide efficient patient care.

Keywords: Cost block, costing of intensive care services, ICU, patient care expenses

\section{INTRODUCTION}

Intensive Care Units (ICUs) of a hospital are specific care areas, where patients are kept under constant monitoring through sophisticated equipment, titrated life support, and well-trained staff experienced in the management of critical situations. ${ }^{[1]}$ It utilizes the skills and expertise of medical, nursing, and paramedical staff to provide utmost care to critically ill patients. ${ }^{[2]}$ Research shows that, due to their nature of service, ICUs consume $34 \%$ of hospital budgets and contributes to a third of total inpatient costs..$^{[3,4]}$ In the absence of comprehensive health insurance coverage, $>80 \%$ of patients have to pay out of their pockets. ${ }^{[5]}$ Hence, lack of proper control measures in intensive care functioning, would not only affect the economic functioning of operations but as well adds up to the health-care bills of patients.

\section{OBJeCtives}

- $\quad$ To identify and compare the cost of patient care among ICUs of a tertiary care teaching hospital

- To compute the running costs of ICUs.

\begin{tabular}{|l|l|}
\hline \multicolumn{2}{|c|}{ Access this article online } \\
\hline Quick Response Code: & Website: \\
\hline & www.ijccm.org \\
\cline { 2 - 2 } & \\
\hline
\end{tabular}

\section{Materials and Methods}

The units under the study, Respiratory ICU (RICU) and Surgical ICU (SICU), were 10-bedded each, serving the respective patient needs.

Retrospective data was collected for 1 year (March 2014 till February 2015) by referring to the records and registers maintained at respective departments, whereas prospective observations were made through staff interactions informally.

In the present study, key factors that majorly influence the cost of services in SICU and RICU were identified. The cost block method of costing was adopted as formulated by Edbrooke, et al., 1999, where the identified key costs of ICU were brought under various segments called as cost blocks. The six major cost blocks were mentioned

Address for correspondence: Asst Prof. Kanakavalli Kiranmai Kundury, Department of Health System Management Studies, Jagadguru Sri Shivarathreeswara University, Mysuru - 570 015, Karnataka, India. E-mail: kanakavalli.dhsms@jssuni.edu.in

This is an open access article distributed under the terms of the Creative Commons Attribution-NonCommercial-ShareAlike 3.0 License, which allows others to remix, tweak, and build upon the work non-commercially, as long as the author is credited and the new creations are licensed under the identical terms.

For reprints contact: reprints@medknow.com

How to cite this article: Kundury KK, Mamatha HK, Rao D. Comparative assessment of patient care expenses among intensive care units of a tertiary care teaching hospital using cost block method. Indian J Crit Care Med 2017;21:85-8. 
as $\mathrm{C} 1$ - equipment costs, $\mathrm{C} 2$ - construction and electricity costs, C3 - nonclinical expenses and salaries to nonclinical staff, C4 - clinical services, C5 - consumable costs, and C6 - salaries of clinical staff. ${ }^{[6]}$ The annual costs of the above were considered, which were further divided into per month and per day (running cost).

\section{Results and Discussion}

\section{Key factors and cost comparisons}

Figure 1 depicts the intra- and inter-unit comparison of patient care expenses in respective ICUs. Construction costs stood as a major cost contributor with $44 \%$ in both the units, keeping laboratory expenses at $22 \%$ in SICU and $28 \%$ in RICU. Since patients in SICU will undergo the necessary laboratory investigations before the surgery, it is less likely for patients to get the re-testing done in postoperative conditions. This could be a factor for less percentage contribution of laboratory expenses in SICU when compared with RICU. Salaries of clinical and nonclinical staff combined together were found to make $11 \%$ in SICU and 10\% in RICU contribution toward the total cost of patient expenses per day, standing as the next highest cost drive.

SICU, being equipment intensive, shows higher contribution of electrical charges with $9 \%$ contribution toward patient care expenses. Considering patient condition, consumable consumption was found to contribute $7 \%$ in SICU and $6 \%$ in RICU toward patient care expenses per day. Imaging services were found to contribute 5\% toward per day expenses in SICU and $4 \%$ in RICU. Linen and CSSD per day expenses were found to be minimal with $1 \%$ contribution when compared with other cost factors.

\section{C1: Equipment costs}

A total of 79 equipment in SICU and 68 equipment in RICU were considered, which includes ventilators, cardiac monitors, syringe pumps, infusion pumps, nebulizers, defibrillators, and electrocardiogram machines. The total cost of equipment was divided proportionately among all the equipment to compute the unit cost of each and 10\% depreciation was also considered. Since the equipment are brand new, working still under valid warranty periods, and annual maintenance contract being included during purchase, the percentage contribution of equipment was found to be minimal toward per day patient care expenses in SICU and RICU.

\section{C2: Estate and electricity costs}

The elements which aid in the effective and efficient functioning of ICUs, namely, land, utilities, engineering and maintenance, interiors and exteriors of the building, were considered under estate costs. In the current study, the area of SICU and RICU was obtained as $2928.44 \mathrm{sq} \mathrm{ft}$ and $3377.55 \mathrm{sq} \mathrm{ft}$, respectively, and the cost of construction per $100 \mathrm{sq} \mathrm{ft}$ as 1.5 lakhs. The total cost of constructing SICU and RICU which included civil, electrical, and mechanical aspects of infrastructure was computed by multiplying the land area by cost of construction. The total cost thus obtained was divided into per day, which was found to contribute $44 \%$ toward overall patient care expenses per day in respective ICUs as in Figure 1.

The present study shows electricity contributing 9\% toward patient care expenses per day in SICU and 6\% in RICU. Annual consumption cost of electricity was computed which was further divided into per month and per day costs.

\section{C3: Nonclinical expenses}

Nonclinical services including linen and laundry, housekeeping, dietary, and sterile supplies are the support services, which play an indispensable role for efficient patient care services. ${ }^{[7]}$ In the current study, the contribution of linen cost toward the patient care expenses per day was found to be minimal as $1 \%$ in comparison to other expenses of SICU and RICU.

The cost of medium sterile supplies was found to be negligible when compared to other expenses. Salaries of nonclinical staff include housekeeping, security, and porters who work round the clock to aid in patient care. According to Figure 1, this cost segment contributed to $5 \%$ of per day cost of running SICU and $4 \%$ in RICU.

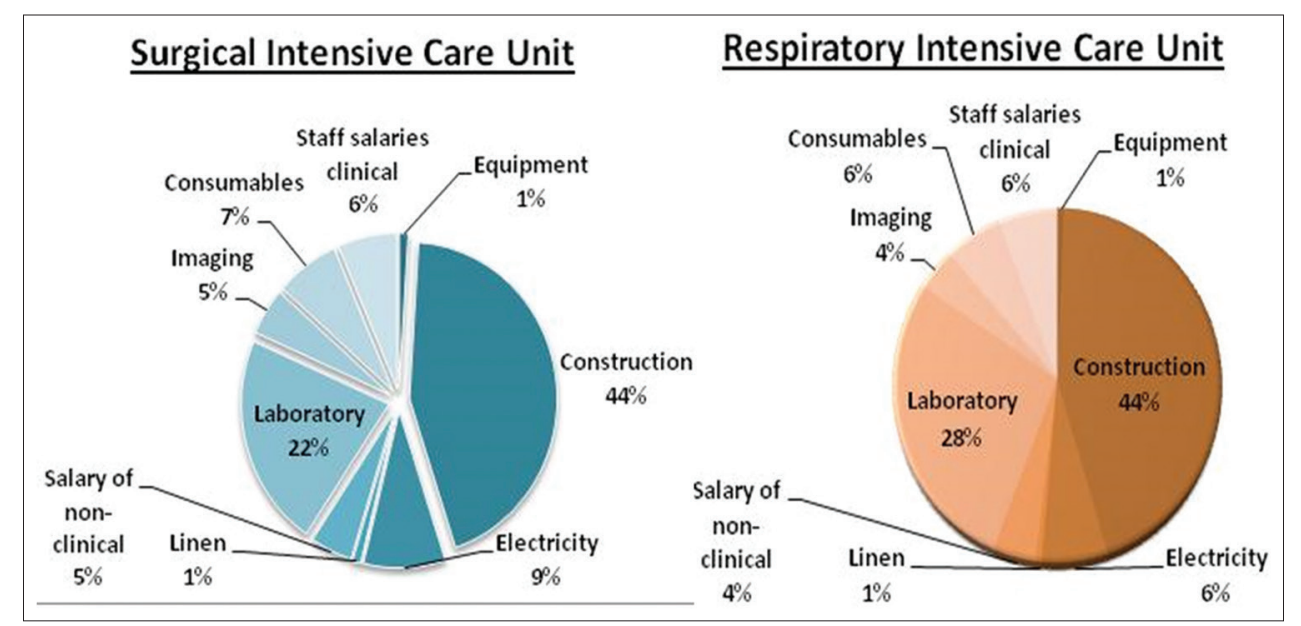

Figure 1: Cost comparisons between Surgical Intensive Care Unit and Respiratory Intensive Care Unit. 
C4: Clinical expenses: Laboratory and imaging services According to Table 1 and Figure 2, number of biochemical and microbiological investigations and their costs were relatively higher in RICU than in SICU. Pathological tests were slightly high in SICU, while total cost of pathological investigations were marginally equal in both the units. Although imaging services from SICU showed relatively low number when compared to RICU, total cost of those services was a bit higher in SICU than RICU. According to Figure 1, laboratory investigations showed $22 \%$ contribution toward per day patient expenses in SICU and $28 \%$ in RICU. Imaging services accounted for $5 \%$ in SICU and $4 \%$ in RICU. This cost block from the UK research showed only $5 \%-7 \%$ of total ICU resource utilization. ${ }^{[6]}$

\section{C5: Consumables}

Consumables include pharmaceutical supplies, blood and blood products, fluids and nutrition; and disposables needed for patient care. ${ }^{[6]}$ The current study has considered consumables as emergency drugs, disposables, stationary, cleaning and disinfecting materials which were procured by respective ICU's on monthly indent basis. Thus, consumables accounted for $7 \%$ of patient care expenses in SICU and 6\% in RICU when compared with other cost factors as per Figure 1.

\section{C6: Salaries of clinical staff}

Research shows that staff cost consumes $>50 \%$ of the running costs and budgets of ICUs. ${ }^{[4,5,8,9]}$ As per Figure 1, the percentage contribution of clinical staff salaries was found to be $6 \%$ in both SICU and RICU toward per day patient care expenses.

\begin{tabular}{lcc}
\hline \multicolumn{3}{l}{ Table 1: Laboratory and Imaging services } \\
\hline & Total Investigations & Total cost (Rs) \\
\hline SICU & 5153 & 1341719 \\
Biochemistry & 816 & 451230 \\
Microbiology & 2600 & 383940 \\
Pathology & 952 & 480380 \\
Imaging & & \\
RICU & 6535 & 1987858 \\
Biochemistry & 1821 & 793560 \\
Microbiology & 2106 & 356580 \\
Pathology & 1052 & 452695 \\
Imaging & &
\end{tabular}

Combined salaries of clinical and nonclinical staff show $11 \%$ in SICU and $10 \%$ in RICU toward per day expenses. Considering clinicians salaries would enhance these figures to be comparable with earlier research results.

\section{Overview of cost blocks associated with Respiratory Intensive Care Unit and Surgical Intensive Care Unit}

Figure 3 expresses that cost block 2 was a major contributor to per day expenses in SICU and RICU when compared with other cost blocks. Cost block 4 was the second highest contributor to per day expenses in both the units; where RICU showed higher contribution than SICU. Cost block 5 and 6 were standing equal while cost block 3 was relatively low when compared with other cost blocks.

\section{Running cost of Intensive Care Units}

The running cost of ICUs was computed by summing up the components under various cost block heads, which was found to be as Rs. 27,371.89 in SICU and Rs. 31,183.86 in RICU. This was found to be reasonably comparable with earlier research results..${ }^{[4,9]}$ Comparison among the units has shown that RICU, though having equal bed strength as SICU, Has higher running cost. It was identified that laboratory and imaging expenses of RICU played an important role toward this.

\section{Conclusion}

Intensive care areas are major resource consumption areas that have to be carefully managed throughout. Identifying its importance in patient care, the present study was conducted

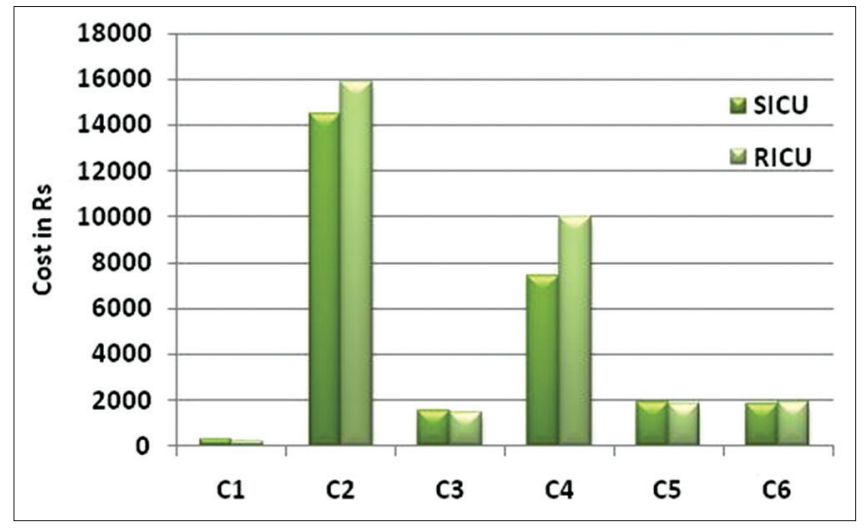

Figure 3: Cost block comparison between SICU and RICU.

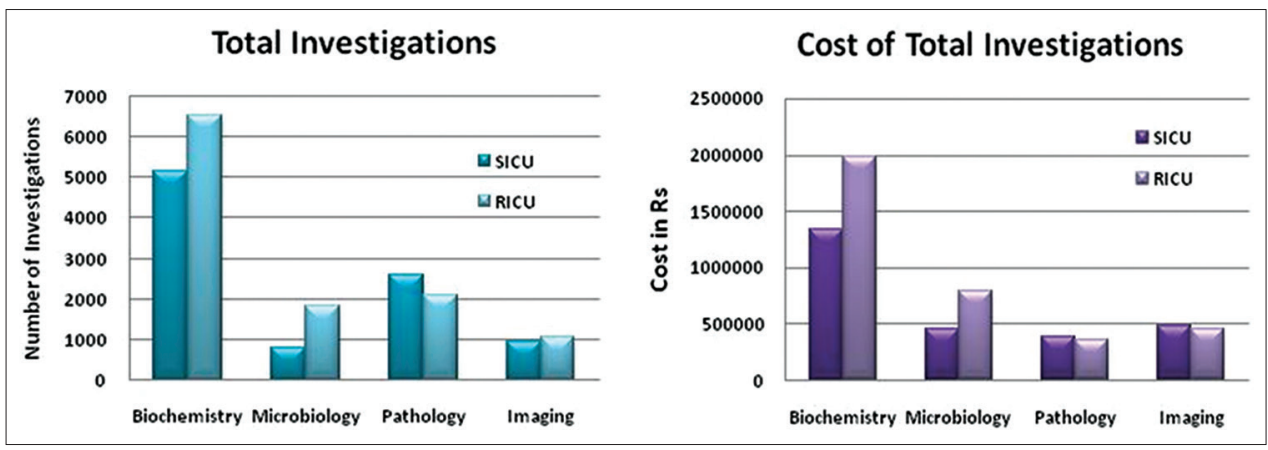

Figure 2: Comparison of patient investigations between SICU and RICU. 
to facilitate management in cost control measures as well for affordable patient care.

\section{Financial support and sponsorship}

Nil.

\section{Conflicts of interest}

There are no conflicts of interest.

\section{References}

1. Joshi DC, Joshi M. Hospital Administration. $1^{\text {st }}$ ed. New Delhi, India: Jaypee Publications; 2009. p. 198-9.

2. Yeolekar ME, Mehta S. ICU care in India - Status and challenges. J Assoc Physicians India 2008;56:221-2.

3. Multz AS, Chalfin DB, Samson IM, Dantzker DR, Fein AM, Steinberg HN, et al. A "closed" medical Intensive Care Unit (MICU) improves resource utilization when compared with an "open" MICU. Am J Respir Crit Care Med 1998;157 (5 Pt 1):1468-73.
4. Shweta K, Kumar S, Gupta AK, Jindal SK, Kumar A. Economic analysis of costs associated with a Respiratory Intensive Care Unit in a tertiary care teaching hospital in Northern India. Indian J Crit Care Med 2013;17:76-81.

5. Jayaram R, Ramakrishnan N. Cost of intensive care in India. Indian J Crit Care Med 2008;12:55-61.

6. Edbrooke D, Hibbert C, Ridley S, Long T, Dickie H. The development of a method for comparative costing of individual Intensive Care Units. The Intensive Care Working Group on Costing. Anaesthesia 1999;54:110-20.

7. Narang A, Kiran PS, Kumar P. Cost of neonatal intensive care in a tertiary care center. Indian Pediatr 2005;42:989-97.

8. Divatia JV, Baronia AK, Bhagwati A, Chawla R, Iyer S, Jani CK. Critical care delivery in Intensive Care Units in India: Defining the functions, roles and responsibilities of a consultant intensivist. Indian J Crit Care Med 2006;10:53-63.

9. Kundury KK, Mamatha HK, Rao D. Assessing the patient care expenses and cost per bed of a medical Intensive Care Unit (MICU) of a tertiary care teaching hospital using cost block method. Int J Manage $2015 ; 6: 59-70$ 